Journal of Applied Pharmaceutical Science Vol. 5 (07), pp. 112-117, July, 2015

Available online at http://www.japsonline.com

DOI: 10.7324/JAPS.2015.50717

ISSN 2231-3354 (cc) BY-NC-SA

\title{
Formulation and Characterization of Ketoprofen Emulgels
}

\author{
Ramakanth Ambala, Sateesh Kumar Vemula \\ ${ }^{1}$ Department of Pharmaceutics, Chaitanya College of Pharmacy Education and Research, Kishanpura, Hanamkonda, Warangal, Andhra Pradesh, India. \\ ${ }^{2}$ College of Medical and Health Sciences, Wollega University, Post Box No: 395, Nekemte, Ethiopia.
}

\begin{tabular}{|c|c|}
\hline ARTICLE INFO & ABSTRACT \\
\hline $\begin{array}{l}\text { Article history: } \\
\text { Received on: } 06 / 02 / 2015 \\
\text { Revised on: } 22 / 03 / 2015 \\
\text { Accepted on: } 09 / 04 / 2015 \\
\text { Available online: } 27 / 07 / 2015\end{array}$ & $\begin{array}{l}\text { The present study was intended to formulate the ketoprofen emulgels using different viscosity grades of } \\
\text { hydroxypropyl methylcellulose and carbopol as gelling agents. All the prepared emulgels were shown acceptable } \\
\text { physical properties concerning colour, homogeneity, consistency, and pH value. Emulgels containing } \\
\text { hydroxypropyl methylcellulose were poor in clarity when compared to carbopol formulations. The influence of } \\
\text { the type of gelling agent on the drug release from the prepared emulgels was investigated and carbopol } 934\end{array}$ \\
\hline $\begin{array}{l}\text { Key words: } \\
\text { Carbopol, Controlled release, } \\
\text { Hydroxypropyl } \\
\text { methylcellulose, Stability } \\
\text { studies, Similarity index, } \\
\text { Topical administration. }\end{array}$ & $\begin{array}{l}\text { release studies, } \mathrm{F} 3 \text { formulation showed } 98.46 \pm 2.05 \% \text { drug release in } 8 \mathrm{~h} \text { with good clarity and physical } \\
\text { appearance. The T10\% and T80\% values of best formulation } \mathrm{F} 3 \text { was found to be } 0.9 \mathrm{~h} \text { and } 6.6 \mathrm{~h} \text { respectively. } \\
\text { The T10\% and } \mathrm{T} 80 \% \text { was higher for formulations with carbopol in low concentration when compared to } \\
\text { hydroxypropyl methylcellulose } \mathrm{K} 4 \mathrm{M} \text { and } \mathrm{K} 15 \mathrm{M} \text { in high concentrations, indicating better controlled release. } \\
\text { FTIR studies proved the compatibility between drug and carbopol. From the stability studies, similarity index } \\
\text { value between dissolution profiles of } \mathrm{F} 3 \text { formulation before and after storage was found to be } 87.16 \text {. Hence the } \\
\text { development of ketoprofen emulgels is a suitable way for topical administration. }\end{array}$ \\
\hline
\end{tabular}

\section{INTRODUCTION}

Topical administration facilitates safe and effective delivery of drug molecules with lower doses when compared with that of oral dosage forms. Another potential advantage topical dosage forms is the optimization of drug concentration at the desirable sites, reducing the chances of side effects. Topical preparation is used for the localized effect at the site of their application by virtue of drug penetration into the underlying layer of skin or mucous membrane (Chien, 1992). Within the major group of semisolid preparations, the use of transparent gels has expanded both in cosmetics and in pharmaceutical preparations (Vyas et al., 2002). In recent years, there has been great interest in the use of novel polymers with complex functions as emulsifiers and thickeners because the gelling capacity of these compounds allows the formulation of stable emulsions and

\footnotetext{
* Corresponding Author

Sateesh Kumar Vemula, Department of Pharmaceutics, Chaitanya

College of Pharmacy Education and Research, Kishanpura,

Hanamkonda, Warangal, Andhra Pradesh, India-506001

Email:vemulasatish15@gmail.com
}

creams by decreasing surface and interfacial tension and at the same time increasing the viscosity of the aqueous phase. As the name suggests, emulgels are the combination of emulsion and gel. When gels and emulsions are used in combined form the dosage forms are referred as emulgel (Khullar et al., 2011; Mohamed, 2004a). Both oil-in-water and water-in-oil emulsions are used as vehicles to deliver various drugs to the skin (Rieger et al., 1986). The presence of a gelling agent in the water phase converts a classical emulsion into an emulgel (Khullar et al., 2012). Emulgels for dermatological use have several favorable properties such as being thixotropic, greaseless, easily spreadable, easily removable, emollient, non-staining, water-soluble, longer shelf life, biofriendly, transparent \& pleasing appearance. Use of topical agents requires an appreciation of the factors that influence percutaneous absorption (Stanos, 2007). Many widely used topical agents like ointments, creams lotions have many disadvantages. They have very sticky causing uneasiness to the patient when applied. Moreover they also have lesser spreading coefficient and need to apply with rubbing. And they exhibit the problem of stability also (Cecv, 2008). Due to all these factors within the major group of semisolid preparations, the use of transparent gels and emulgels has expanded both in cosmetics and in pharmaceutical preparations. 
Some of the recent research examples for emulgels are diclofenac acid and its salts (Wang et al., 2008), Chlorphenesin (Mohamed, 2004b), Clotrimazole (Mostafa et al., 2011), Rofecoxib (Desai, 2004), Fluconazole (Bachhav et al., 2009) and Piroxicam (Khunt et al., 2012).

Ketoprofen is a member of non-steroidal antiinflammatory drugs and shows strong analgesic and anti-pyretic effect. Ketoprofen causes gastrointestinal disturbances, peptic ulceration with bleeding, if present in large doses in gastrointestinal tract upon oral administration (Singh et al., 2009; Patil et al., 2004). The topical application allows for a higher local concentration of the drug at the site of initiation of the pain and lower or negligible systemic drug levels producing fewer or no adverse drug effects (Nikumbh et al., 2013; Hosny et al., 2013). Emulgels have emerged as a promising drug delivery system for the delivery of hydrophobic drugs. By considering the above factors, the present study is intended to develop the ketoprofen emulgel using carbapol 940 and hydroxypropyl methylcellulose (HPMC K4M \& K15M) as a gelling agent to overcome the gastric side effects and achieve the therapeutic benefit.

\section{MATERIALS AND METHODS}

\section{Materials}

Ketoprofen and Carbopol 934, HPMC K4M and HPMC $\mathrm{K} 15 \mathrm{M}$ are obtained as a gift sample from MSN Laboratories, Hyderabad, India. All other chemicals used were of analytical grade.

\section{Preparation of ketoprofen emulgels}

Ketoprofen emulgel was prepared using carbopol 940, HPMC K4M and HPMC K15M as gelling agents (Table 1). The gels in formulations were prepared by dispersing carbopol or HPMC in purified water with constant stirring at a moderate speed and then the $\mathrm{pH}$ are adjusted to around 6 using tri ethanol amine. The oil phase of the emulsion was prepared by dissolving span 20 in light liquid paraffin while the aqueous phase was prepared by dissolving tween 20 in purified water. Methyl and propyl parabens were dissolved in propylene glycol whereas drug was dissolved in ethanol and both solutions were mixed with the aqueous phase. Both the oily and aqueous phases were separately heated to $70^{\circ}$ to $80^{\circ} \mathrm{C}$; then the oily phase were added to the aqueous phase with continuous stirring until cooled to room temperature. Finally the emulgel was prepared by mixing the both gel and emulsion in 1:1 ratio (Baibhav et al., 2011; Sabri et al., 2009).

\section{Physical evaluation of emulgels}

The prepared ketoprofen emulgel formulations were inspected visually for their colour, clarity, homogeneity, $\mathrm{pH}$ and viscosity. All developed gels were tested for colour, clarity and homogeneity by visual inspection after the gels have been set in the container. They were tested for their appearance to identify the presence of any aggregates. The $\mathrm{pH}$ values of $1 \%$ aqueous solutions of the prepared emulgel were measured by a $\mathrm{pH}$ meter
(Digital pH meter, Systronics). The $\mathrm{pH}$ of emulgels is adjusting to avoid the risk of irritation upon application to the skin and the acceptable $\mathrm{pH}$ is around 5.5 (Panwar et al., 2011). Viscosity measurements were carried out at room temperature $\left(25-27^{\circ} \mathrm{C}\right)$ using a Brookfield viscometer (Model RVTDV II).

\section{Determination of drug content}

The prepared emulgels were tested for the drug content uniformity. Accurately weighed quantity of formulation was transferred to a $100 \mathrm{ml}$ volumetric flask containing $50 \mathrm{ml}$ of methanol and allowed to stand for $5 \mathrm{~h}$ with intermittent sonication to ensure complete solubility of the drug. The mixture was made up to volume with methanol. The solution was suitably diluted and the absorption was determined by UV-Visible spectrophotometer at $260 \mathrm{~nm}$.

\section{Spreadability}

Spreadability is used to express the extent of area to which gel readily spread on application to skin or affected part and the therapeutic efficacy of a formulation also depends upon its spreading value. Spreadability was determined by wooden block and glass slide apparatus. Weights about $20 \mathrm{~g}$ were added to the pan and the time were noted for upper slide (movable) to separate completely from the fixed slides. Spreadability was then calculated by using the formula:

\section{$\mathbf{S}=\mathbf{M} \mathbf{x} \mathbf{L} / \mathbf{T}$}

Where, $\mathrm{S}=$ Spreadability; $\mathrm{M}=$ Weight tide to upper slide; $\mathrm{L}=$ Length of glass slide; $\mathrm{T}=$ Time taken to separate the slide completely from each other (Jain et al., 2010).

\section{Swelling index}

To determine the swelling index of prepared emulgels, 1 gm of gel is taken on porous aluminum foil and then placed separately in a $50 \mathrm{ml}$ beaker containing $10 \mathrm{ml} 0.1 \mathrm{~N}$ sodium hydroxide. Then samples were removed from beakers at different time intervals and put it on dry place for some time after it reweighed. Swelling index is calculated as follows:

\section{Swelling Index $(\mathrm{SW}) \%=[(\mathrm{Wt}-\mathrm{Wo}) / \mathrm{Wo}] \times \mathbf{1 0 0}$}

Where $(\mathrm{SW}) \%=$ Equilibrium percent swelling, $\mathrm{Wt}=$ Weight of swollen emulgel after time $t, W_{0}=$ Original weight of emulgel at zero time (Khalil et al., 2011).

\section{In vitro drug release studies}

Franz diffusion cell (with effective diffusion area 3.14 $\mathrm{cm}^{2}$ and $15 \mathrm{ml}$ cell volume) was used for the drug release studies. Emulgel (200 mg) was applied onto the surface of cellophane membrane evenly. The membrane was clamped between the donor and the receptor chamber of diffusion cell. The receptor chamber was filled with freshly prepared buffer $\mathrm{pH} 5.5$ solutions to solublize the drug. The receptor chamber was stirred by magnetic stirrer. The samples $(1.0 \mathrm{ml}$ aliquots $)$ were collected at suitable time interval. Samples were analyzed for drug content by UV visible spectrophotometer at $260 \mathrm{~nm}$ after appropriate dilutions. 
Table 1: Formulation of ketoprofen emulgels.

\begin{tabular}{|c|c|c|c|c|c|c|c|c|}
\hline Ingredients (\% w/w) & F1 & F2 & F3 & F4 & F5 & F6 & F7 & F8 \\
\hline Ketoprofen & 1 & 1 & 1 & 1 & 1 & 1 & 1 & 1 \\
\hline Carbopol 934 & 0.25 & 0.5 & 0.75 & 1 & - & - & - & - \\
\hline HPMC K4M & - & - & - & - & 2.5 & 5 & - & - \\
\hline HPMC K15M & - & - & - & - & - & - & 2.5 & 5 \\
\hline Liquid paraffin & 7.5 & 7.5 & 7.5 & 7.5 & 7.5 & 7.5 & 7.5 & 7.5 \\
\hline Tween 20 & 0.5 & 0.5 & 0.5 & 0.5 & 0.5 & 0.5 & 0.5 & 0.5 \\
\hline Span 80 & 0.5 & 0.5 & 0.5 & 0.5 & 0.5 & 0.5 & 0.5 & 0.5 \\
\hline Propylene glycol & 5 & 5 & 5 & 5 & 5 & 5 & 5 & 5 \\
\hline Ethanol & 2.5 & 2.5 & 2.5 & 2.5 & 2.5 & 2.5 & 2.5 & 2.5 \\
\hline Methyl paraben & 0.003 & 0.003 & 0.003 & 0.003 & 0.003 & 0.003 & 0.003 & 0.003 \\
\hline Propyl paraben & 0.001 & 0.001 & 0.001 & 0.001 & 0.001 & 0.001 & 0.001 & 0.001 \\
\hline Water & Q.S. & Q.S. & Q.S. & Q.S. & Q.S. & Q.S. & Q.S. & Q.S. \\
\hline
\end{tabular}

Table 2: Physical evaluation of ketoprofen emulgels (Mean $\pm \mathrm{SD}, \mathrm{n}=3$ )

\begin{tabular}{|c|c|c|c|c|c|c|}
\hline Formulations & Clarity & Colour & Homogeneity & pH & Viscosity (cps) & $\%$ Drug content \\
\hline $\mathrm{F} 1$ & +++ & Off white & Good & $5.8 \pm 0.26$ & $9495 \pm 12$ & $99.83 \pm 1.68$ \\
\hline $\mathrm{F} 2$ & +++ & Off white & Good & $5.4 \pm 0.16$ & $9512 \pm 16$ & $98.56 \pm 0.78$ \\
\hline F3 & +++ & Off white & Good & $5.5 \pm 0.31$ & $9756 . \pm 11$ & $99.86 \pm 0.52$ \\
\hline F4 & +++ & Off white & Good & $5.4 \pm 0.24$ & $9634 \pm 17$ & $98.47 \pm 1.12$ \\
\hline F5 & ++ & White & Good & $5.3 \pm 0.28$ & $9326 \pm 14$ & $99.46 \pm 0.92$ \\
\hline F6 & ++ & White & Good & $5.7 \pm 0.62$ & $9394 \pm 18$ & $98.63 \pm 0.68$ \\
\hline F7 & + & White & Good & $5.4 \pm 0.45$ & $9687 \pm 11$ & $99.12 \pm 0.23$ \\
\hline F8 & + & White & Good & $5.8 \pm 0.12$ & $9512 \pm 13$ & $98.33 \pm 0.45$ \\
\hline
\end{tabular}

Table 3: Drug release kinetics parameters of selected emulgel formulations.

\begin{tabular}{|c|c|c|c|c|c|}
\hline $\begin{array}{c}\text { Formulation } \\
\text { Code }\end{array}$ & $\begin{array}{c}\text { Zero order } \\
\left(\mathbf{R}^{2}\right)\end{array}$ & $\begin{array}{c}\text { First order } \\
\left(\mathbf{R}^{2}\right)\end{array}$ & $\begin{array}{c}\text { Higuchi } \\
\left(\mathbf{R}^{2}\right)\end{array}$ & T10\% (h) & T80\% (h) \\
\hline F3 & 0.9163 & 0.8911 & 0.9724 & 0.9 & 6.6 \\
\hline F6 & 0.9292 & 0.8591 & 0.9512 & 0.7 & 6.1 \\
\hline F8 & 0.9254 & 0.8856 & 0.9538 & 0.8 & 6.4 \\
\hline
\end{tabular}

R2- Correlation coefficient, T10\%-Time to release $10 \%$ drug release and T $80 \%$-Time to release $80 \%$ drug release.

Table 4: Stability studies of F3 emulgel formulation-physical evaluation.

\begin{tabular}{|c|c|c|c|c|c|c|}
\hline Time Period & Clarity & Homogeneity & pH & Spreadability & Viscosity (cps) & \% Drug content \\
\hline Before storage & +++ & Good & $5.5 \pm 0.31$ & $52 \pm 0.68$ & $9756 . \pm 11$ & $99.86 \pm 0.52$ \\
\hline After 3 months & ++ & Good & $5.4 \pm 0.18$ & $51 \pm 0.48$ & $9742 . \pm 11$ & $98.91 \pm 0.72$ \\
\hline
\end{tabular}

Table 5: Stability studies of F3 emulgel formulation-drug release studies.

\begin{tabular}{|c|c|c|c|c|}
\hline Time (h) & Before storage & After 3 months & t-test at $0.05 \mathrm{LS}$ & Similarity Factor (F2) \\
\hline 0 & $0.00 \pm 0.00$ & $0.00 \pm 0.00$ & & \\
\hline 0.5 & $3.89 \pm 0.41$ & $3.12 \pm 0.32$ & & \\
\hline 1 & $12.18 \pm 0.76$ & $11.54 \pm 0.56$ & & \\
\hline 2 & $27.18 \pm 1.35$ & $25.95 \pm 0.98$ & & \\
\hline 3 & $31.72 \pm 1.18$ & $30.26 \pm 0.85$ & Not Significant & 87.16 \\
\hline 4 & $38.90 \pm 1.62$ & $37.67 \pm 1.24$ & & \\
\hline 5 & $47.81 \pm 2.01$ & $46.92 \pm 0.76$ & & \\
\hline 6 & $75.93 \pm 2.32$ & $74.84 \pm 1.18$ & & \\
\hline 8 & $98.46 \pm 2.05$ & $97.51 \pm 0.45$ & & \\
\hline
\end{tabular}

\section{In vitro drug release kinetics}

To elucidate the drug release pattern and mechanism from the prepared formulations, the data obtained from the in vitro dissolution studies was integrated to zero order, first order and Higuchi models (Valluru et al., 2008). Then the dissolution data was also used to calculate the $\mathrm{T} 10 \%$ and $\mathrm{T} 80 \%$ (time in hours to take $10 \%$ and $80 \%$ drug release, respectively) to elucidate the drug release from emulgels (Vemula et al., 2013a; Vemula et al., 2014a).

\section{FTIR study}

The infrared spectra of ketoprofen, physical mixture of drug and polymers were recorded between 400 to $4000 \mathrm{~cm}^{-1}$ on
FTIR to detect the drug-excipients interactions. The FTIR spectra for the test samples were obtained using $\mathrm{KBr}$ disk method using an FTIR spectrometer. The resultant spectra were compared for any possible changes in the peaks of the spectra.

\section{Stability studies}

With the help of ICH guidelines, the stability studies were planned to assess the stability of ketoprofen in emulgels. Three replicates of $\mathrm{F} 3$ formulation was sealed in aluminum coated inside with polyethylene pack and stored at $40 \pm 2{ }^{\circ} \mathrm{C}$ and $75 \pm 5 \%$ $\mathrm{RH}$ in the humidity chamber for three months (Chaudhary et al., 2011). Specimens were gathered following three months of storage and estimated for the all physical evaluation parameters and in 
vitro dissolution rate (Mathews, 1999). Then to prove the stability of dosage form, the similarity index was calculated between dissolution rates of optimized tablets before and after storage. The similarity factor $\left(\mathrm{F}_{2}\right)$ is a logarithmic reciprocal square root transformation of the sum of squared error and is a measurement of the similarity in the percent $(\%)$ of dissolution between the two curves. It is calculated using the following formula. At this point, the data was statistically analyzed using paired $t$-test to test the significance of difference at level of significance 0.05 (Vemula et al., 2013b; Vemula et al., 2014b).

$F_{2}=50 \times \log \left\{\left[1+(1 / n) \sum_{t=1}{ }^{n}\left(R_{t}-T_{t}\right)^{2}\right]^{-0.5} \times 100\right\}$

\section{RESULTS AND DISCUSSION}

\section{Evaluation of ketoprofen emulgel}

The prepared ketoprofen emulgels (F1-F8) were evaluated for clarity, colour, $\mathrm{pH}$, spreadability, viscosity, homogeneity and drug content. F3 has shown better results in $\mathrm{pH}$, spreadability, homogeneity, high viscosity and drug content. The prepared ketoprofen emulgel formulations were white viscous creamy preparation with a smooth and homogeneous appearance. The $\mathrm{pH}$ values of all prepared formulation ranged from 5.3 to 5.8, which are considered acceptable to avoid the risk of irritation upon application to the skin because adult skin $\mathrm{pH}$ is 5.5 . Spreadability values were shown in Figure 1.

The viscosity of prepared formulations was found in the range of $9326 \pm 14$ to $9756 . \pm 11$ cps. In all the formulations, formulations with carbopol showed high viscosity that indicates carbopol as the better gelling agent in low concentration when compared to HPMC formulations. The drug content of all emulgel formulations was found above 98\%. All the above physical parameters of F1-F8 formulations were given in below Table 2.

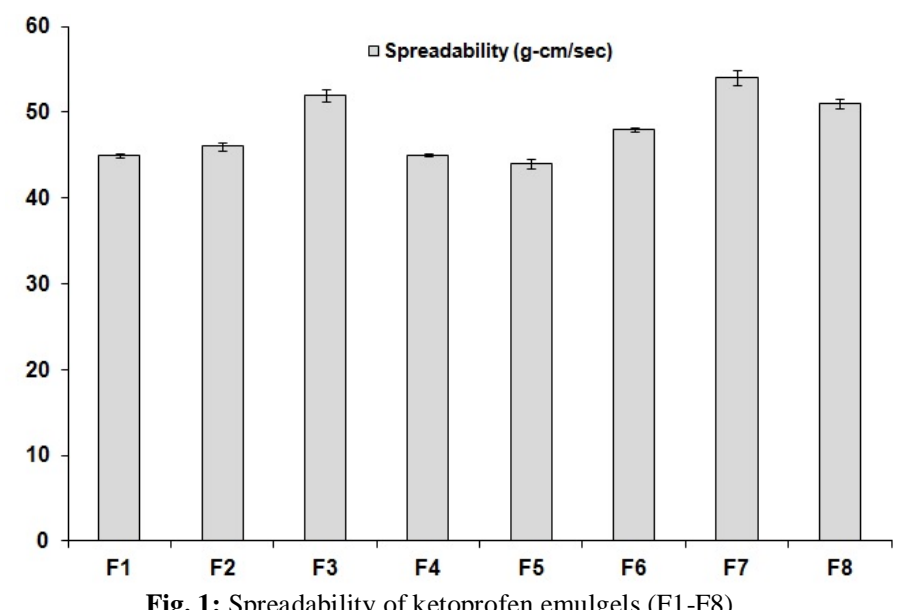

\section{Swelling index}

From the swelling studies, the formulations with carbopol showed maximum swelling index in comparison of HPMC formulations. Among the all formulations, F3 emulgel formulation showed highest swelling index properties in comparison of other it means emulgel formulating having greater swelling tendency i.e. tendency to from wound. Similar type of observation was found in a study by Ghodekar et al., 2011. The swelling index values of all formulations were given in Figure 2 .

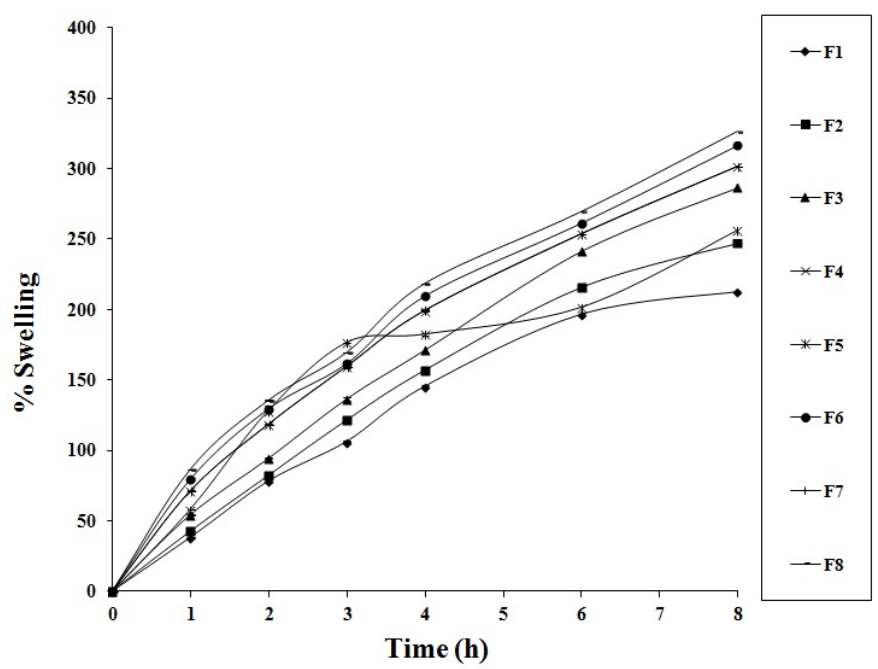

Fig. 2: Percent swelling of ketoprofen emulgels (F1-F8)

\section{In vitro drug release study}

The in vitro drug release studies carried out for all the formulations and Figure 3 and 4 represents the drug release from carbopol and HPMC. The study showed the release of the drugs from its emulsified carbopol gel formulation can be ranked in the following descending order: F1 $>$ F2 $>$ F3 $>$ F4 where the F3 formulation showed highest drug release after $8 \mathrm{~h}(98.46 \pm 2.05 \%)$. Similar type of results were observed in a study by Khullar et al., 2012 i.e., mefenamic acid emulgel using carbopol.

To give similar type of drug release in case of HPMC based emulgel preparations, they required high concentration of polymer than carbopol. Thus the F3 formulation containing carbopol is considered as the better formulation among all other formulations.

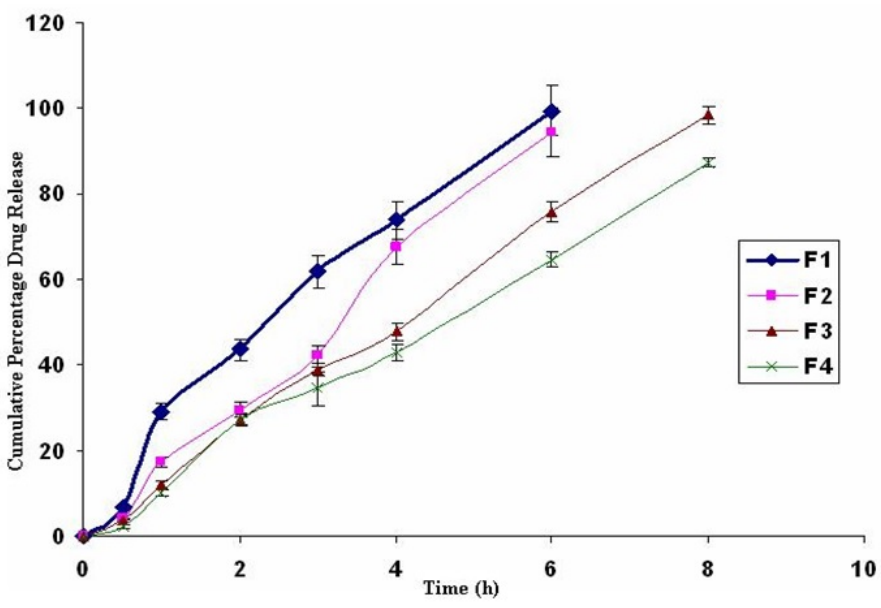

Fig. 3: Percent drug release of ketoprofen from carbopol emulgels. 


\section{In vitro drug release kinetics}

The drug release mechanism and kinetics was determined by the application of Higuchi's model, zero order and first order kinetics. Most of the emulgel formulations showed high $r^{2}$ values for Higuchi's model as their $\mathrm{r}^{2}$ values were between 0.9724 and 0.9538 .

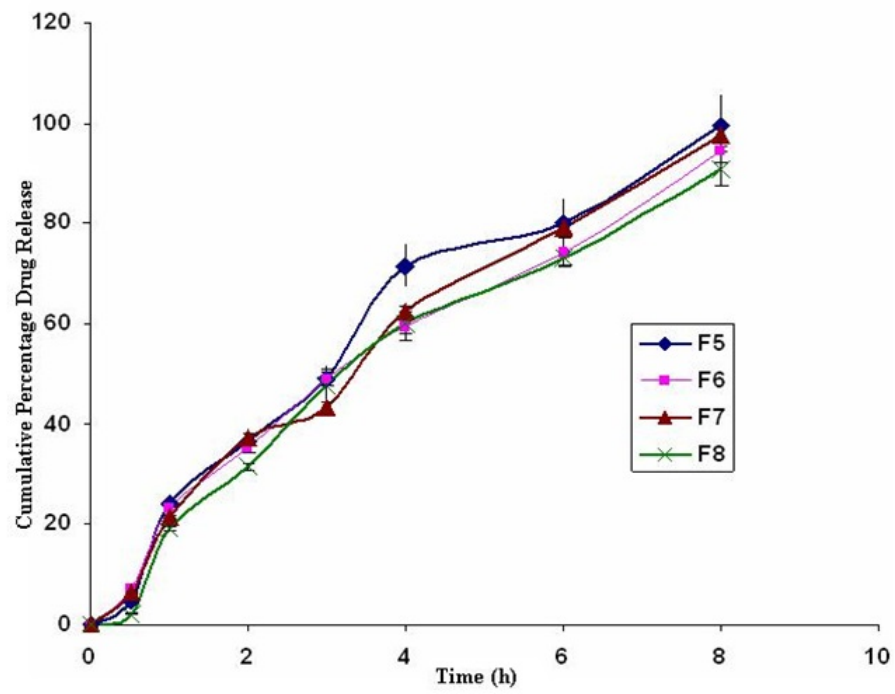

Fig. 4: Percent drug release of ketoprofen from HPMC emulgels.

The high regression value of Higuchi model ensured that the release of drug from emulgels followed diffusion mechanism. The $\mathrm{T} 10 \%$ and $\mathrm{T} 80 \%$ values of best formulation F3 was found to be $0.9 \mathrm{~h}$ and $6.6 \mathrm{~h}$ respectively. The $\mathrm{T} 10 \%$ and $\mathrm{T} 80 \%$ was higher for formulations with carbopol in low concentration when compared to HPMC K $4 \mathrm{M}$ and $\mathrm{K} 15 \mathrm{M}$ in high concentrations, indicating better controlled release. Time in hours to take $10 \%$ and $80 \%$ drug release (T10\% and T80\%) explained the ability of prolonged release. All these results were given in Table 3.

\section{FTIR study}

The infrared spectra of ketoprofen, physical mixture of drug and polymers were recorded and shown in Figure 5. From the results, FTIR spectra showed that there were no interactions identified between drug and polymers. From the FTIR spectral analysis all the principal peaks observed in pure drug were present in the FTIR spectra of the F3 formulation and some additional peaks were observed with physical mixtures, which could be due to the presence of polymer. No drug-polymer interaction was observed in the FTIR spectra of the powder mixture of best formulation since the absorption peaks of the drug still could be detected in the mixture.

\section{Stability studies}

The stability studies data was represented in Table 4 and 5. All the prepared emulgel formulations were found to be stable upon storage for three months, no change was observed in their physical appearance, clarity, $\mathrm{pH}$, viscosity, spreadability and drug content. After storage of six months, the formulation was subjected to in vitro drug release studies (Table 5) and from the statistical analysis there was no significant difference between before and after storage $(P<0.05)$. The similarity index value between dissolution profiles of optimized formulation before and after storage was found to be 87.16. The similarity index value was found as more than 50 indicate similarity between the dissolution profile before and after storage.

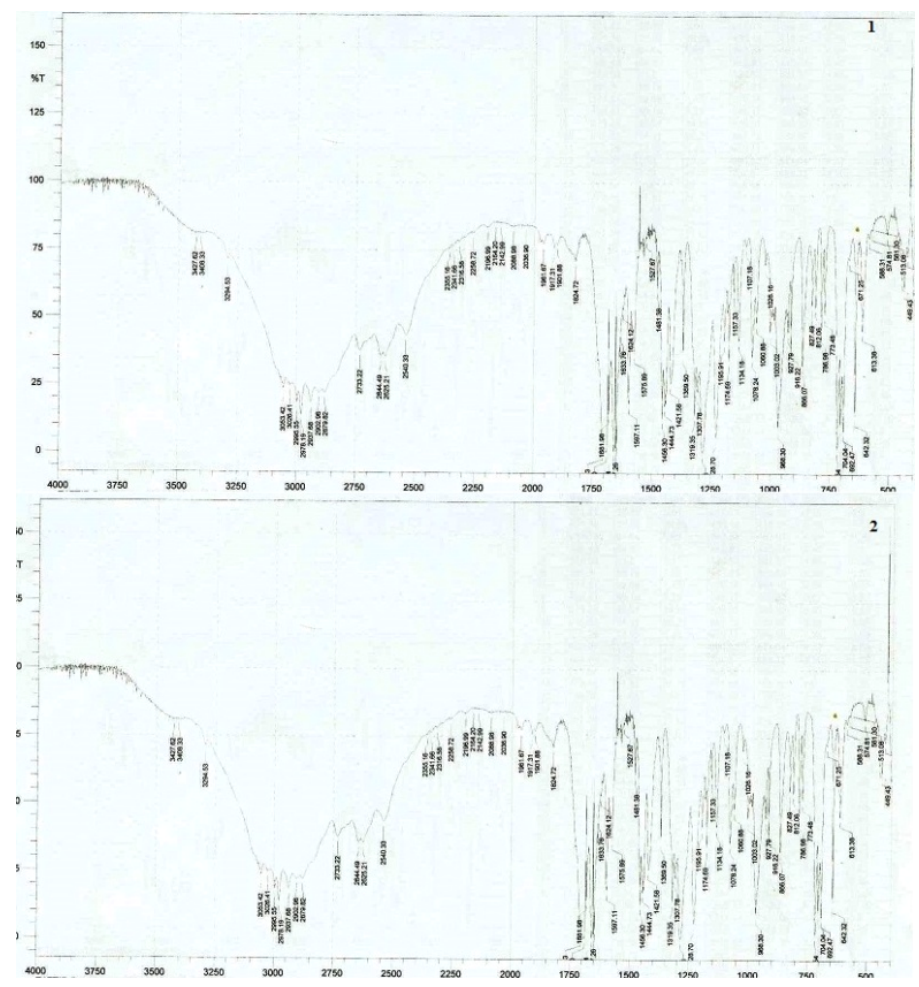

Fig. 5: FTIR spectra of 1) pure ketoprofen and 2) physical mixture of drug and carbopol.

\section{CONCLUSION}

Emulgels, considered as the recent technique for the topical drug delivery, are better suitable for the delivery of hydrophobic drugs and combination of both hydrophilic and hydrophobic drugs. Mainly the hydrophobic drug formulation can be developed with Emulgel technique because it contain both oil and aqueous (i.e. gel phase) on the other hand hydrogel are not suitable for hydrophobic drugs. In the present study ketoprofen emulgels were prepared using carbopol and HPMC as gelling agents. All the formulations were characterized for different parameters and formulations with carbopol shown better results when compared to HPMC as gelling agent. From the in vitro drug release studies, formulation F3 showed maximum drug release of $98.46 \pm 2.05 \%$ in $8 \mathrm{~h}$ with good physical properties. FTIR studies proved that there were no possible interactions between ketoprofen and carbopol. From the stability studies, after storage the F3 formulation was observed in stable form. Thus the formulation of carbopol emulgels was considered as the good approach for topical delivery of drugs like ketoprofen. 


\section{ACKNOWLEDGEMENTS}

The authors acknowledge the MSN Laboratories, Hyderabad, India for gift samples. The authors also thank to Management Chaitanya College of Pharmacy Education and Research for providing facilities.

\section{REFERENCES}

Bachhav Y., Patravale V. Microemulsion based vaginal gel of fluconazole: formulation, in vitro and in-vivo evaluation. Int J Pharmaceut. 2009; 365: 175-179.

Baibhav J., Rana G., Vikas S. Comprehensive review on the recent advances in topical drug delivery. Int Res J Pharm. 2011; 66-70.

Cecv G. Preclinical characterisation of NSAIDS in ultra deformable carriers or conventional topical gels. Int J Pharm. 2008; 15201621.

Chaudhary A., Tiwari N., Jain V., Singh R. Microporous bilayer osmotic tablet for colon-specific delivery. Eur J Pharmaceut Biopharmaceut. 2011; 78(1): 134-140.

Chien YW. Novel drug delivery systems. 2nd ed. Marcel Dekker, New York (1992).

Desai K. Enhanced skin permeation of rofecoxib using topical microemulsion gel. Drug Dev Res. 2004; 63: 33-40.

Ghodekar SV., Chaudhari SP., Ratnaparakhi MP. Development and characterization of silver sulfadiazine emulgel for topical drug delivery. Int J Pharm Pharm Sci. 2012; 4(4): 305-316.

Hosny KM., Rambo SM., Al-Zahrani MM., Al-Subhi SM., Fahmy UA. Ketoprofen emulgel: preparation, characterization, and pharmacodynamic evaluation. Int Pharm Sci Rev Res. 2013; 20(2): 306310

Jain A., Gautam SP., Gupta Y., Khambete H., Jain S. Development and characterization of ketoconazole emulgel for topical drug delivery. Der Pharmacia Sinica. 2010; 1 (3): 221-231.

Khalil YI., Khasraghi AH., Mohammed EJ. Preparation and evaluation of physical and, rheological properties of clotrimazole emulgel: Iraqi J Pharm Sci. 2011; 20(2): 19-27.

Khullar R., Saini S., Sethi N., Rana AC. Emulgel A surrogate approach for topically used hydrophobic drugs. Int J Pharm Biol Sci. $2011 ; 117-128$

Khullar R., Kumar D., Seth N., Saini S. Formulation and evaluation of mefenamic acid emulgel for topical delivery. Saudi Pharmaceut J. 2012; 20: 63-67.

Khunt DM., Mishra AD., Shah DR. Formulation design \& development of piroxicam emulgel. Int J PharmTec Res. 2012; 4(3): 13321344.

Mathews BR. Regulatory aspects of stability testing in Europe. Drug Dev Ind Pharm. 1999; 25(7): 831-856.

Mohamed MI. Topical emulsion gel composition comprising diclofenac sodium. AAPS J. 2004a; 6(3): 254-262.

Mohamed MI. Optimization of chlorphenesin emulgel formulation. AAPS J. 2004b; 6(3): article 26.

Mostafa S., Seham AH., Mohammad H., Nahed M. Novel jojoba oil-based emulsion gel formulations for clotrimazole delivery. AAPS PharmSciTech. 2011; 12(1). 239-247.
Nikumbh KV, Sevankar SG, Patil MP. Formulation development, in vitro and in vivo evaluation of microemulsion-based gel loaded with ketoprofen. Drug Deliv. 2013 Nov 25. (Epub ahead of print).

Panwar AS., Upadhyay N., Bairagi M., Gujar S., Darwhekar GN., Jain DK. Emulgel: A review. Asian J Pharm Life Sci. 2011; 1(3): 333-343

Patil P., Joshi P., Paradkar A. Effect of formulation variables on preparation and evaluation of gelled self-emulsifying drug delivery system (SEDDS) of ketoprofen. AAPS PharmSciTech. 2004; 5(3): 43-50.

Rieger MM, Lachman L, Lieberman HA, Kaing JL. The theory and practice of industrial pharmacy. 3 rd ed. PA Lea and Febiger, Philadelphia (1986) 502-533.

Sabri LA., Sulayman HT., Khalil YI. An Investigation release and rheological properties ofmiconazole nitrate from emulgel. Iraqi $\mathrm{J}$ Pharm Sci. 2009; 18(2): 26-31.

Singh S., Gajra B., Rawat M., Muthu MS. Enhanced transdermal delivery of ketoprofen from bioadhesive gels. Pak J Pharm Sci. 2009; 22(2): 193-198.

Stanos SP. Topical agents for the management of musculoskeletal pain. J Pain Symptom Manage. 2007; 33(3): 342-355.

Valluru R., Siddaramaiah T., Pramod M. Influence of natural polymer coating on novel colon targeting drug delivery system. J Mat Sci. 2008; 19: 2131-2136.

Vemula SK., Veerareddy PR. Formulation, evaluation and pharmacokinetics of ketorolac tromethamine time-dependent colon targeted drug delivery system. Exp Opin Drug Del. 2013a; 10(1): 33-45.

Vemula SK., Bontha VK. Colon targeted gaur gm compression coated tablets of flrbiprofen: Formlation, development and pharmacokinetics. Bio Med Res Int. 2013b; Article ID 287919.

Vemula SK., Veerareddy PR., Devadasu VR. Pharmacokinetics of colon-specific $\mathrm{pH}$ and time-dependent flurbiprofen tablets. Eur J Drug Met Pharmacokinet. 2014a; DOI 10.1007/s13318-014-0210-0.

Vemula SK., Veerareddy PR., Devadasu VR. Pharmacokinetics of ketorolac tromethamine compression-coated tablets for colon delivery. Drug Del Trans Res. 2014b; 4: 310-319.

Vyas SP, Khar RK, Controlled drug delivery: concepts and advances. 1st ed. Vallabh Prakashan, India (2002) 411-447.

Wang M., Fang L. Percutaneous absorption of diclofenac acid and its salts from emulgel. Asian J Pharmaceut Sci. 2008; 3(3): 131-141.

\section{How to cite this article:}

Ramakanth Ambala, Sateesh Kumar Vemul. Formulation and Characterization of Ketoprofen Emulgels. J App Pharm Sci, 2015; 5 (07): 112-117. 